Results Eighty-eight cases were indentified which represents $9.6 \%$ of total hospitalizations during the study period. The sex ratio was 1,4 . Fifty four percent $(n=48)$ of cases were associated to bacteraemia and only 2 cases of meningitis were noted. Infectious risk factors were acute fetal hypoxia (42\%), peripartum maternal fever $(35,2 \%)$ and membrane rupture more than 12 hours before delivery $(26,1 \%)$. Sixteen percent of all newborns were premature and $19,3 \%$ had a low birth weight. $64.8 \%$ were symptomatic at birth. The main clinical signs were respiratory distress $(82.5 \%)$, neurologic distress (17.5\%) and fever (12.3\%).

Assisted ventilation was required in 11 patients, 5 of whom died. Predictive factors for bad prognosis were prematurity (2case), severe hypoxemia (2case), nosocomial infections (1case).

Conclusions We noted a decrease in the mortality rate, due to advances in the neonatal care. However, neonatal streptococcal $B$ infections still remain a significant problem of public health requiring additional preventive and therapeutic management based on systematic screening and antibiotic prophylaxis.

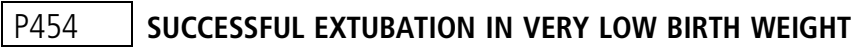 INFANTS IN A TERTIARY NEONATAL INTENSIVE CARE UNIT}

'A Jenkinson*, 'D Sweetman, ${ }^{1,2}$ LK McCarthy. 'Department of Neonatology, The National Maternity Hospital, Dublin, Ireland; ${ }^{2}$ School of Medicine and Medical Science, University College Dublin, Dublin, Ireland

\subsection{6/archdischild-2019-epa.790}

Introduction Prompt extubation of mechanically ventilated very low birth weight infants (VLBW) in the NICU, when clinically ready is in infants' best interest. It can be difficult to predict which infants will extubate successfully. No one bedside test or clinical sign has proven useful as a predictive tool. Reported rates of extubation failure in preterm infants are as high as $50 \%$. At our level 3 NICU the decision to extubate an infant is at the discretion of the clinical team; there are no set extubation criteria. We aimed to determine the rate of successful extubation at our hospital; and to describe any clinical markers associated with extubation success or failure.

Methods This retrospective review was carried out at the National Maternity Hospital, between January $1^{\text {st }}$ and December $31^{\text {st }} 2017$. VLBW infants with a birth weight $(B W) \leq 1500$ $\mathrm{g}$, that were mechanically ventilated and had a planned extubation attempt during their admission were included. For each individual we included data from the first extubation attempt only.

Results Of the 146 infants $\leq 1500 \mathrm{~g}$ admitted to the NICU, 56 (38\%) were intubated and $48(33 \%)$ had a planned extubation attempt. The mean (SD) gestational (GA) of the 48 included infants was 28(2) weeks, BW 1097(261)g. Extubation was successful in $82 \%$ of infants and was associated with higher GA and $\mathrm{BW}$, and shorter duration of ventilation. At re-intubation, $80 \%$ of infants had an additional co-morbidity.

\begin{tabular}{|c|c|c|c|}
\hline Characteristics & $\begin{array}{l}\text { Successful } \\
N=40\end{array}$ & $\begin{array}{l}\text { Unsuccessful } \\
\mathrm{N}=8\end{array}$ & P Value \\
\hline GA, wks ${ }^{a}$ & $28(2)$ & $25(1)$ & $<0.001$ \\
\hline$B W, g^{a}$ & $1123(241)$ & 807 (204) & 0.002 \\
\hline Inborn $^{b}$ & $36(90)$ & $6(75)$ & 0.258 \\
\hline Male ${ }^{b}$ & $16(40)$ & $5(62)$ & 0.272 \\
\hline Delayed cord clamping $\geq 30$ seconds $^{\mathrm{b}}$ & $31(81)^{*}$ & $4(57)^{*}$ & 0.172 \\
\hline SVD & $16(40)$ & $6(75)$ & 0.077 \\
\hline Duration of mechanical ventilation, hours ${ }^{c}$ & $42(19-147)$ & $132(70-169)$ & 0.026 \\
\hline Surfactant $(E T T)^{b}$ & $38(95)$ & $8(100)$ & 0.990 \\
\hline Caffeine & $40(100)$ & $8(100)$ & \\
\hline Postnatal steroids ${ }^{\mathrm{b}}$ & $16(40)$ & $6(75)$ & 0.077 \\
\hline $\mathrm{FiO}_{2}$ pre-extubation ${ }^{\mathrm{a}}$ & $0.23(0.03)$ & $0.27(0.06)$ & 0.069 \\
\hline
\end{tabular}

${ }^{a}$ Mean (SD), ${ }^{b} \mathrm{~N}(\%),{ }^{c}$ Median (IQR); * Missing data

Conclusion The rate of extubation success at our NICU is higher than previously reported. There are multiple potential reasons for this including tertiary antenatal care, few outborn infants, completed courses of ANS, postnatal steroid use; or a conservative approach to extubation. A higher GA and BW, and shorter duration of mechanical ventilation were associated with extubation success.

\section{P455 A RETROSPECTIVE AUDIT LOOKING AT HAEMATOLOGICAL ABNORMALITIES IN CHILDREN BORN WITH DOWN SYNDROME IN A TERTIARY MATERNITY HOSPITAL}

Sarah Kyne*, Anna Curley. Neonatal Department, National Maternity Hospital, Holles Street, Dublin, Ireland

\subsection{6/archdischild-2019-epa.791}

Background Haematological abnormalities are common in children with Down Syndrome (T21). In the neonatal period, babies can present with polycythemia, neutrophilia and thrombocytopenia. There is also a 150-fold increased risk of myeloid-leukaemia of Down Syndrome usually presenting before five years ${ }^{1}$. This is seen by a transient abnormal myeloposis (TAM), unique to T21, and associated with the haematopoietic transcription factor gene GATA $1^{1}$. There are increased blast cells $(>10 \%)$ however, silent presentations do still occur with infants developing ML-DS with $<10 \%$ blast cells on film ${ }^{1}$.

Aim In this audit, we aimed to examine the haematological abnormalities of babies with T21 born in our centre. Our guidelines state that all children with a suspected diagnosis of T21 should have a full blood count (FBC) carried out in the first few days of life. If there are abnormalities, a blood film is carried out as routine and patients with significant abnormalities are discussed directly with a haematology consultant for further management.

Methods A retrospective lab audit in a tertiary maternity hospital of all 42 babies diagnosed with T21 over a two-year 